\title{
AMORES INTERTEXTUALES Y PARODIAS POSMODERNISTAS: VICENTE MOLINA FOIX Y LA POESÍA
}

\author{
CANDElas Gala \\ Wake Forest University
}

\section{RESUMEN}

Tomando como punto de partida los dos libros de poesía, Los espías del realista y Vanas penas de amor, que Vicente Molina Foix publica en 1990 y 1998, respectivamente, este ensayo analiza el papel de la mirada irónica que el hablante poético dirige a los modelos literarios, artísticos y culturales sólidamente establecidos en el sistema analítico y referencial de la tradición. La lectura atenta de poemas específicos procedentes de ambas colecciones revela el uso que hace Molina Foix de estrategias paródicas e intertextuales para desbancar la monumentalidad de dichos discursos con el fin no tanto de descartarlos y ridiculizarlos, sino más bien de mostrar su incongruencia en el contexto moderno y a nivel de la persona individual.

Palabras Clave: Ironía, parodia, intertextualidad, postmodernismo, discurso analíticoreferencial.

\section{INTER-TEXTUAL ROMANCES AND POSTMODERNIST PARODIES: VICENTE MOLINA FOIX AND POETRY}

\begin{abstract}
Taking as a point of departure the two poetry books, Los espías del realista y Vanas penas de amor, that Vicente Molina Foix published in 1990 and 1998, respectively, this essay analyzes the role of the ironic glance the poetic speaker casts on the literary, artistic and cultural models firmly rooted in the analytical-referential system of tradition. A careful reading of specific poems from both collections reveals Molina Foix's use of parodic and inter-textual strategies to debunk the monumentality of such discourses, not so much to ridicule or do away with them, but to show their incongruence in the modern context and at the level of the individual person.
\end{abstract}

Key words: Irony, parody, inter-textuality, postmodernism, analytico-referential discourse.

Uno de los misterios más discutidos sobre la biografía del poeta latino Ovidio es la razón de su exilio a Tomis. De entre las varias teorías, la más aceptada mantiene que Ovidio no fue exiliado por cometer un crimen, sino por haber sido testigo de algún acto que implicaba al emperador Augusto y po- 
nía en riesgo su poder ${ }^{1}$. El mirar o ver, que tan caro le costó a Ovidio, es protagonista central en los poemas y novelas de Vicente Molina Foix quien sin referirse directamente al romano comparte con él intereses, actitudes y técnicas literarias. Ambos dirigen su irónica mirada sobre el amor, la sexualidad y sus aventuras y no tienen reparos en demoler creencias establecidas ${ }^{2}$ Ambos concuerdan con Umberto Eco en que para visitar el pasado hay que dejar de lado la inocencia y proveerse de un buen grado de ironía (pp. 38-39). Esta vuelta al pasado, que según Eco es la respuesta postmodernista al modernismo, implica una recreación paródica por la que se vislumbra el desencanto del sujeto poético y la incertidumbre de su entorno. Como se verá en el análisis de poemas específicos de Molina Foix, la parodia no descarta el idealismo de valores establecidos ni la preeminencia de los modelos literarios y artísticos; tampoco se limita a ridiculizarlos. Lo que hace es mostrar su incongruencia en el mundo moderno y a nivel individual.

El lugar central de la mirada en la revisión paródica de Molina Foix se evidencia en el título mismo de su primer libro de poemas, Los espías del realista (1990), mientras que muchos de los personajes en sus novelas o son detectives o se sirven de telescopios, prismáticos y catalejos para observar su entorno $^{3}$. Este espionaje se duplica en el texto mismo mirándose en otros textos a los que refleja y a la vez distorsiona. En el poema programático con que se abre la colección, «Lo nunca visto» (pp. 15-16), el hablante poético, «apostado en el rincón / del mundo» ha decidido «abrir / bien los ojos» para vigilar su entorno. Desde ese espacio límite, correspondiente a la escritura como experiencia liminal que según Julia Kristeva caracteriza al postmodernismo («writing as experience of limits», «Postmodernism?», p. 137), este sujeto fija su mirada en escenas que luego narra en sus poemas y que implican cuestiones sobre textos e intertextos, sexualidad e intersexualidad, subjetividad e

\footnotetext{
${ }^{1}$ Según Peter Green, otra posible razón del destierro de Ovidio sería el carácter altamente erótico de sus escritos, especialmente por su defensa del adulterio como juego para la clase social alta. Sus escritos contienen además repetidas críticas contra el régimen de Augusto, sobre todo al proponer el otium frente al programa de regeneración moral del imperio y la sexualidad en lugar de las conquistas militares (pp. 43-44).

${ }^{2}$ Ambos comparten también el gusto por el ingenio, la ironía y la actitud pragmática respecto al sexo. La frivolidad, la parodia, las referencias mitológicas, la dependencia del mundo de los libros que Green identifica en Ovidio (p. 63) se encuentran también en los poemas de Molina Foix. Desde su inclusión en la antología de Castellet sobre los novísimos hasta la publicación de Los espías del realista (1990) y Vanas penas de amor (1998), Molina Foix se ha dedicado más a la prosa siendo autor de nueve novelas. La más reciente, El Abrecartas, ha obtenido el premio Salambó 2006 a la mejor novela en lengua castellana y el premio Nacional de Literatura en Narrativa (2007). Molina Foix colabora también en $E l$ País desde 1976 y es autor de obras de teatro, guionista de cine y director de su primera película, Sagitario (2000) de cuyo guión es responsable.

${ }^{3}$ Carlos, protagonista de La mujer sin cabeza, es detective de profesión y desde la terraza de su piso da sus «ojeos» sobre lo que le rodea (p. 19).
} 
intersubjetividad $^{4}$. Si como en Ovidio hay un exilio para este protagonista, es el del hablante en el postmodernismo con respecto a la tradición que Timothy Reiss llama analítico-referencial y su creencia en un referente fuera de nosotros al que se puede examinar objetivamente (p. 31). El sujeto poético de Molina Foix recurre a la vista y a los instrumentos más comunes en el discurso analítico-referencial (telescopios, catalejos...) para parodiarlos y mostrar que sus propios sentimientos y perspectiva afectan toda pretensión de conocimiento objetivo y distanciado. En vez de llegar a desvelar la «verdad», la vigilancia de este realista topa con una maraña de alusiones, citas e intertextos que dificultan el establecimiento de una verdad única. La creencia en una vista monocular se cuestiona en la experiencia de este realista y sus múltiples espías o versiones estereoscópicas de los hechos. Molina Foix se une así a autores que como Bataille, Sastre y, por supuesto Foucault, dan cuenta de la implicación inevitable del observador en lo observado 5 .

Según Hutcheon, la parodia supone un proceso de revisar, subvertir y «transcontextualizar» obras del pasado (Theory, p. 11). Implica, por tanto un juego intertextual cuya naturaleza, generalmente burlesca e irreverente, se sobrepone a la intimidación que esos textos producen debido a su reconocido valor $^{6}$. Baktin es quien primero introdujo la idea de que cada texto supone la absorción y transformación de otro texto. Michael Rifaterre se sirve del término «hipograma» que bien puede ser un cliché, una cita o un grupo de asociaciones convencionales no localizado en el texto y que, a modo de sistema descriptivo o complejo temático, sirve de base para la intertextualidad del poema y, en casos, para la parodia (p. 164). Gérard Genette, por su parte, se sirve del término «transdiegetización» para describir la transposición semán-

\footnotetext{
${ }^{4}$ Según Linda Hutcheon, el postmodernismo nos obliga a prestar atención al discurso «excéntrico» y a cuestionar lo que se impone como central y totalizador pues los sistemas por los que nos organizamos son provisionales, no naturales (Poetics, p. 41). Diana Fuss analiza la dualidad de lo de dentro y lo de fuera, indicando que cuanto mayor es el vacío del centro más pie se da al discurso marginal como forma de encubrirlo.

${ }^{5}$ Véase el ensayo de Martin Jay sobre la mala prensa de la vista en el siglo XX, particularmente en la crítica francesa. El debilitamiento de lo ocular pone en entredicho la supuesta transparencia del lenguaje y el carácter unitario del sujeto (p. 66). Este realista vigilante es ejemplo de lo que Kosinski llama la autoficción del sujeto, forma postmodernista de la escritura que reconoce el elemento biográfico o «auto» porque el sujeto adopta para sí la naturaleza ficticia de su protagonista, y el ficcionalizar como proceso implícito en toda reconstrucción artística (cit. Hutcheon, Poetics, p. 10). Para García-Posada (pp. 16-17) se trata de una ficcionalización relativa al haber una separación consciente entre el yo poético y el yo real. Lanz habla del «marco de ficción» que se crea en la relación dialógica del poeta y su lector donde no se trata de «confesión» sino de «fabulación» (pp. 154-156).

${ }^{6}$ Hablando de los novísimos, Sagredo Saldaña opta por describir su obra como «poesía cultural» en vez de «culturalismo poético», expresión que normalmente se aplica a ese grupo cuyos miembros se vuelven al pasado para liberarlo de una autorictas que lo hace rígido e inamovible. Como afirma el crítico, «su cultura no es necesariamente culta» («Poesía española postmoderna», p. 152).
} 
tica, o cambio de diégesis, cuando el texto actual altera el marco históricogeográfico del texto antecedente o hipotexto con el fin, a menudo, de actualizar referentes. Así ocurre en el caso de Molina Foix donde temas tradicionales se sitúan en un contexto actual y se articulan en un lenguaje igualmente contemporáneo (p. 196). A veces se da también un proceso de «transmotivación» por el que el motivo central del hipotexto se cambia adquiriendo un sentido denigrante, paródico y, como señala Lanz, de pastiche por lo vacío de su contenido (Genette, pp. 372-375; Lanz, pp. 151-152). Darío Villanueva acuñó el término de «escritura palimpsestuosa» para referirse a las muchas formas de recreación que caracteriza la escritura española de los últimos veinte años en la que se incluye la obra de Molina Foix (ver también Culler, The Pursuit, p. 83) 7 .

Los espías del realista es un libro consciente de su organización. Contiene cinco secciones con un poema de introducción y otro de cierre, con citas epígrafes para las tres primeras secciones y para el poema inicial, y títulos para las secciones cuatro y cinco. Responde a la preferencia por el texto orgánico que caracteriza la nueva poesía (García Posada, p. 19). Si el título de la colección, y su supuesta creencia en el conocimiento objetivo y en la vista como aprehensión de una realidad distanciada de la subjetividad se parodia en los poemas específicos, las citas epígrafes establecen una relación paródica con los poemas, mientras que los títulos de algunos poemas son a su vez paródicos. El resultado es un conjunto cuyas partes se aluden y reflejan paródicamentre entre sí. Por ejemplo, el poema de apertura «Lo nunca visto» es donde el sujeto promete «abrir bien los ojos» para vigilar «lo nunca visto». Además va precedido por una dedicatoria a Javier Marías, «que conoce lo que no ocurre» y una cita de Lazarillo de Tormes, «¡Cuántos debe de haber en el mundo que huyen de otros porque no se veen a si mesmos!». Si la dedicatoria desafía la creencia de que el conocimiento se basa en lo que existe o sucede, la cita alude a la otredad en el seno mismo del Yo. El Otro o «lo nunca visto» es lo que se suele eludir a pesar de que su presencia en el Yo es innegable. El Otro corresponde a la inversión que Molina Foix lleva a cabo de los grandes discursos culturales parodiando su aparente unidimensionalidad.

La cita de Sextus Propertius, «Liber eram et vacuo meditabar vivere lecto; at me composita pace fefellit Amor» [Era libre y quería vivir sin compartir mi lecho. Pero después de establecer la tregua, el Amor me engañó], que precede a la primera sección del libro, parodia los intentos de los espías del

${ }^{7}$ Juan Borrás, protagonista de El vampiro de la calle Méjico (2002), reconoce el carácter repetitivo de la parodia cuando, refiriéndose a su trabajo como restaurador de obras de arte, explica: «Esto no es arte, sino academia. Lo mío siempre han sido las copias. Fijarse mucho, y no inventar nada que el otro, el que pintó primero, no hubiese puesto» (p. 314). Ya Barthes dijo que no hay creadores sino «combinateurs» pues el que escribe (o pinta) debe saber que comienza «un long concubinage avec un langage qui est toujours antérieur» (Essais critiques, p. 14). 
realista por revelar la verdad pues con lo que se topan es con el engaño y la duplicidad. A su vez, la cita a Calderón sobre el «amor que después fue incendio, asombro, rayo y tormenta», precede un grupo de poemas que más que esas fuertes pasiones hablan de desgana, dudas, desengaños, e indiferencia. Una cita de Proust antecede la sección «La amenaza del hospital» donde el sadismo, que según Proust proporciona el fundamento en la vida a la estética del melodrama, adquiere su más claro perfil en poemas sobre alguna enfermedad incurable y sus visibles estragos en el rostro del enfermo. Sadismo es también la ausencia de toda marca de enfermedad en los cuerpos aparentemente saludables de los visitantes al hospital aunque ya lleven su mal escondido dentro. El juego entre signos visibles e invisibles de la enfermedad en pacientes y visitantes, respectivamente, parodia la aceptada asociación de lo visible con la verdad y de lo invisible con lo no existente o engañoso. Como la mutua implicación del Yo y el Otro, paciente y visitante son dos caras de la misma moneda ${ }^{8}$.

«Lo nunca visto» identifica tres elementos en la vigilancia del realista: el Corazón, la Espada de los libros y el campo Oscuro de letras vivas. Estos términos sitúan el proyecto de escritura de Molina Foix en relación paralela, y paródica, con un idealismo fácilmente identificado con el mundo de la caballería e incluso de la mística: el Corazón, es decir, la experiencia humana constituye el foco de la empresa; los libros, o literatura, en general, son la Espada con que llevar a cabo la lucha; y las letras vivas es el lenguaje de la vida como campo Oscuro, doble del bosque, selva o noche en la que el héroe tradicional lucha con sus pasiones y enemigos. En el caso del protagonista de Molina Foix tales ideales sufren una reducción paródica al referirse, generalmente, al interés y experiencia personales y a un contexto desprovisto de trascendencia. Las experiencias del Corazón desbaratan el mundo de mitos clásicos y de modelos ideales; el mundo de los libros deja de ser una Espada en defensa de altas miras para volverse instrumento de canjeo en lances amorosos desprovistos de exclusividad, y el lenguaje abandona toda pretensión de autonomía para reclamar su entronque con la vida. La mirada se tiñe de subjetivismo y se vuelve estereoscópica al captar el juego especular y paródico entre los textos.

Como poema de entrada a los tres focos de atención ya designados, «Fin de año» (pp. 21-23) marca en su título la dirección paródica de la colección. En vez del comienzo del año con su promesa de realización, el libro se abre con el fin de otro año y la monotonía anti-vital del paso del tiempo. Este suceder se describe como un proceso «chaquetero» pues con trucos de planes

\footnotetext{
${ }^{8}$ En su estudio sobre Foucault Jay indica que la importancia del ojo en medicina no es tanto para detectar la vitalidad del paciente sino su mortalidad (p. 58). En la sección «La amenaza del hospital» (pp. 75-86) del libro de Molina Foix, los visitantes ven en el amarillo de los rostros y la palidez de los ojos del paciente todas las señales de su muerte.
} 
y proyectos incita a seguir empeñándonos en un vivir que no conduce a ninguna parte. El sujeto le acusa al año de que, sin su permiso, le ha sacado del tinte «la chaqueta de mis empeños», la que se pone en la empresa del vivir, chaqueta de empeños como esfuerzos que son también empeños de crédito tanto financiero como personal al tener que «creer» en valores que, según revela la experiencia, carecen de fundamento. Al sacar del tinte la chaqueta, es decir, la cubierta, su colorido se muestra como pura apariencia. El tiempo le ha jugado una treta al sujeto al poner en evidencia sus estragos en esa chaqueta descolorida. Esta elaboración sobre el paso del tiempo se yuxtapone paródicamente con la oración del Padrenuestro donde el pan de Dios libra de la tentación al proporcionar el alimento físico y espiritual de cada día. En la inversión paródica, de lo que hay que librarse es de la tentación de seguir creyendo en ese mismo vivir diario en el que el tiempo es lo que devora, por mucho pan que se coma. Ahora bien, librarse de la tentación de vivir en el tiempo equivale a la muerte $\mathrm{y}$, paradójicamente, caer en la «tentación» tiene a la larga el mismo fin. Como no hay salida, y en un gesto común a la parodia en este libro, la plegaria pide y, a la vez, se retrae: «Y sobre todo no / me dejes caer / en otra tentación / que la de huir de ti / sin ir muy lejos». Si la «tentación» deja de ser únicamente la caída en el pecado, el pan nuestro de cada día resulta ser menos bendición de lo que se creía.

En torno al Corazón se agrupa una serie de poemas donde la experiencia personal desbanca el idealismo del mundo clásico y de modelos consagrados por la cultura. En «Geórgica» (pp. 24-25) y en «Bucólica» (p. 56), el texto de trasfondo o hipograma es el discurso virgiliano de la naturaleza y su eternidad y del locus amoenus; hay también alusiones a la parábola evangélica sobre la siembra y la cosecha (Marcos, 4: 3-8). El hablante en «Geórgica» ha sembrado sus semillas de amor con la mala suerte de que cuando se disponía a recoger el fruto, el «aire de los tiempos» se llevó a su amante a un campo más trillado. En «Bucólica» la exuberancia del locus amoenus se reduce a «Una naturaleza pequeña / [como] le conviene / a nuestro repentino / y algo escuálido amor». En «Rapto» (pp. 31-32), y con el mito del rapto de Júpiter por Ganímedes como trasfondo, se narra una historia que invierte los papeles tradicionales: el narrador/ Júpiter es raptado por el barman/Ganímedes quien, además, paga la consumición y quien le transporta desde las alturas «celestiales» de su piso (un «pent-house», tal vez) al pequeño sótano «algo patas arriba» de su apartamento. Este cambio de papeles y territorios no ocurre a menudo, como admite el narrador: «Pocas veces ocurre / que un mito / se invierta. / A mí sólo una vez. / Esta es la triste historia». Y triste fue pues al verse en situación tan nueva, este Júpiter no salió tan airoso como se suele decir en las leyendas: «O había apuntado mal / o bien no tiré a dar / o algo mucho peor: el disparo falló». La caza sexual aquí falla debido a un exceso de confianza en la experiencia y posición del narrador; o por pura comodidad. Este Júpiter actual no da la talla del legendario Júpiter triunfalista. 
En «Ruinas en Agrigento» (pp. 48-49) se parodia un lugar asociado con el mundo clásico convertido por el turismo en destino de recién casados. Las parejas ilusionadas visitan el templo de la Concordia donde las musas «más versadas» tuvieron cobijo, para luego oír los auguri agli sposi «entre las mandolinas». Parodiando este trasfondo, el poema narra la Discordia de la pareja que visita Agrigento y que en vez de los buenos deseos para su relación, presencian su ruina. El poema llama la atención sobre el lenguaje como sistema mediante el uso de palabras en italiano (auguri agli sposi, albergo, città alta), y con cambios de letras, como en el juego de casa/caso/cosa, concordia/discordia, o con la referencia al paso desde Hispanoamérica, donde se inició el idilio hasta Agrigento, donde termina. La facilidad con que un mero cambio de idioma, vocal o continente afecta el significado indica la fragilidad de todo sistema de identidad. Las musas «más versadas» del templo de la Concordia en Agrigento pueden «versarse» o girar en dirección contraria, y las columnas del templo podrían tambalearse «a la primera brisa de otra Historia». Las ruinas de Agrigento dan testimonio de la permanencia del pasado en el presente pero su sentido no es estable, como se supondría. La historia y el pasado mezclan su sentido con la experiencia personal y el ámbito de la subjetividad; al hacerse presente, el pasado se renueva y cambia (Hutcheon, Poetics, p. 20).

«El fantasma opera» (pp. 50-51) es otro poema donde se juega con las palabras pues aunque el título hace referencia al musical del mismo nombre y lo mantiene en el trasfondo, «opera» alude al verbo «operar» o «funcionar». Como en El fantasma de la ópera, el fantasma tiene un efecto, es decir «opera» en la protagonista y también en el narrador del poema, a pesar de su sábana arrugada y de hilos poco tupidos con carreras en el tejido. Este amante, fantasma de capa caída, arrastra una bola del mundo que está rota, señalando así el deterioro de su estado a nivel mundial. Y sin embargo, aun tiene poder para afectar al hablante recordándole un pasado cuando con ropas bien planchadas impresionaba «a los ingenuos / que creen / en los cuentos / del amor». Aunque el sujeto reconoce, por un lado, que es ingenuo creer en «los cuentos del amor», por otro confiesa que aún le asusta haber visto a su antiguo amante. El fantasma del amor «opera» en el narrador a pesar de sus aires de estar de vuelta de todo; no es, entonces, el fiable narrador de los hechos pues sus emociones están implicadas en lo que narra.

Los seis versículos en «Seis platonismos» (pp. 62-63) están dedicados a desbancar principios conocidos del platonismo. Frente al amor idealista se propugna el gustar sexualmente (versículo I); y los ojos como espejo del alma y fuente de contemplación y admiración del amado se reducen a una simple «historia del ojo», alusión a Histoire de l'oeil, la novella de Georges Bataille sobre dos jóvenes cuyos experimentos sexuales les llevan a la perversión y también, posiblemente, al ensayo de Roland Barthes «Metaphore de l'oeil» sobre la importancia del ojo en las relaciones y su canjeo con otros objetos 
ovulares como huevos y testículos (versículo II). La situación del diálogo platónico con el maestro que habla y el discípulo que escucha se denuncia como un «Duelo de los amantes sordomudos» pues, como diría Barthes, este hablante denuncia la desigualdad en el diálogo platónico a favor de un principio igualitario de la distribución de los bienes lingüísticos (Fragments d'un discours amoureux, p. 243; versículo III). La compenetración que se dice de los amantes en el plano espiritual reduce el amor a una adivinanza (versículo IV), mientras que los decires sobre el amante maduro y su control de la relación por su dinero se trastocan cuando el protagonista dice que aún siendo joven es él quien paga (versículo V). Finalmente, la unión de las almas en el amor platónico se suplanta por la de los cuerpos con la parodia remate de que ni siquiera la unión física es posible pues la carne misma separa: el pas à deux está cojo.

En torno a la Espada de los libros se agrupan poemas donde el valor tradicionalmente asociado con la cultura literaria se desbanca ante intereses personales. En «Matchmaking» (págs. 29-30), en vez de las cintas, puntillas o hilos celestinescos como fichas de canjeo en el arreglo sexual, las armas de este «visitador de los enamorados» son sus propios libros: «parejas estables / que se cogen la mano agradecidas» exhiben en sus aparadores los libros que él ha escrito con dedicaciones de amor eterno de su puño y letra. O bien se trata de prendas de vestir como «la chaqueta de punto / tejida a mano / que regalé a mi amante / por Reyes / llevada por otro», o rastros de orgías pasadas: «unas manchas de vomitona mía / en el entarimado / de la alcoba / que hoy me está prohibida». El «matchmaking» se vuelve un tráfico de cuerpos, ropa, libros, fluidos y deshechos ${ }^{9}$. En este intercambio, los libros pierden el valor que se les suele atribuir como marcas de cultura; su autor aparece igualmente desacreditado pues lo que regaló como muestra de amor se está usando de segunda mano y, respecto al amor, se descarta toda pretensión de sentimiento único y exclusivo. Más que «Espada» en defensa del «Corazón»e integridad de los sentimientos, los libros aquí actúan como piezas de uso y consumo cuyo único valor es su capacidad de intercambio.

«Epigrama de las dudas» (pp. 45-46) se construye sobre el trasfondo del discurso psicológico en torno a la división en el centro de la subjetividad, sobre la parábola evangélica del trigo y la cizaña (Mateo, 13: 24-30), sobre la filosofía moral del término medio como sede de la virtud, y sobre la duda existencial ${ }^{10}$. Estos hipotextos tienen que ver con la personalidad y constitu-

${ }^{9}$ Sagredo Saldaña habla de una «literatura de la moral otra» para referirse al tratamiento de temas sexuales y eróticos en la poesía postmoderna y su desafío a todo sistema de poder (No todo es superficie, pp. 193-202). Como se da en éste y otros poemas de Molina Foix, la experiencia amorosa se aborda desde posiciones alejadas de la norma hegemónica.

10 Según Coleridge, un poeta admirado por Molina Foix, un epigrama es «a dwarfish whole. Its body brevity, and wit its soul». (http://www.brainyquote.com/quotes/authors/s/ samuel_taylor_coleridge.html) 
ción de la subjetividad y con las opciones que hay que hacer según el sentido que se tenga de lo que es moral. La inversión paródica del poema excluye toda consideración de conducta moral a partir de la reflexión atenta y responsable sobre distintos caminos a seguir para favorecer lo que más conviene al interés personal. El hablante no quiere tener que elegir a uno de entre dos amantes en su vida a sabiendas de que uno de ellos, como la cizaña de la parábola evangélica, no le conviene. Ni siquiera se plantea la necesidad de elegir lo que es moralmente correcto pues lo que cuenta es satisfacer el deseo propio. Si la división del «yo» en psicología y filosofía se debe a tener que optar entre tendencias de signo opuesto (espíritu/cuerpo, bien/mal etc.), y el sujeto ejerce su responsabilidad moral en la decisión tomada, aquí se evita la decisión para satisfacer el deseo egoísta de gozar de todas las opciones posibles. El término medio como teoría de la moderación y virtud se convierte en repartición entre ambos amantes: unos días de la semana los pasará con uno, el resto con el otro, descansando los domingos, como en la Biblia. Más que en la moderación en sí, la virtud reside en calcular cuidadosamente la manera de moderar el deseo con el fin de obtener lo que se quiere sin privarse de nada. La declaración final: «Ya me lo dijo el médico / desde la cabecera / de mi primer diván: 'un yo muy dividido'», se burla de la carga humana del discurso psicológico haciendo del diván del psiquiatra un equivalente de la cama compartida con múltiples amantes. La angustia sartreana o la división y vacío lacanianos se transcontextualizan en la división no por falta, sino por exceso.

En «Epigrama segundo» (p. 47) el «tú» en la relación amoroso-sexual queda atrapado en la maraña del «me dicen» $\mathrm{y}$ «cuentan»: «Me dicen que te acuestas con todo el mundo y los que encuentro cuentan que te han tenido entre sus brazos. A todos les hablabas de mi al desnudarte». Como la transmisión oral de cualquier texto, la imagen del amante le llega al sujeto afectada por las distintas versiones y recuentos, hasta el punto de que no reconoce en el joven de labios rojos y bello pelo castaño claro de que le hablan al amante que él conoció y quien en su recuerdo tenía labios blancuzcos con propensión a pupas y pelo tirando a negro con caspa. ¿Quién es entonces este amante? Su imagen no puede depender de la memoria, instrumento afectado por el tiempo, los celos, el orgullo y otras emociones implicadas en las relaciones fallidas. El tráfico de discursos y cuerpos disuelve toda pretensión de recuerdo indeleble y único del «tú» y de su relación con el «yo» No por nada este poema se titula «Epigrama segundo» ya que la versión original es inaprensible. De persona concreta el «tú» ha pasado a ser alguien en torno a quien se desarrollan discursos (Hutcheon, Poetics, p. 145). De manera similar en «Reencuentro al ser amado en una librería de lance» (pp. 64-65), los libros

Los epigramas de Molina Foix (éste y «Epigrama segundo») no son poemas largos pero tampoco tienen la brevedad del epigrama convencional aunque sí el ingenio y humor. 
pierden su carga intelectual para volverse instrumentos mediadores en la relación de amor. En esta librería donde se venden libros a buen precio el lance es, además, el del reencuentro de dos antiguos amantes y la sorpresa del más maduro, el narrador, al ver que el que fue su joven amante mantiene la afición a la lectura que él le inculcó. Por eso con sorpresa se pregunta, «¿Habré hecho / de ti una lumbrera? / ¿Un futuro / talento / de las letras?» Si así fuera, el sujeto ya no tendría ninguna autoridad sobre el joven en base de su mayor edad, experiencia y conocimientos, y podría darse el caso de competencia entre ambos. Aunque, como dice el narrador, «No alcancé a leer / el lomo de / los tomos / que ojeabas», la referencia marca los libros y sus lomos de connotaciones sexuales. No sólo el discípulo ha desplegado sus propias alas sino que el antiguo maestro no tiene acceso más a sus «lomos». A pesar de su supuesta madurez y conocimientos, el narrador no está encajando bien el lance de la nueva situación, por tanto, se hace un voto a sí mismo que en la próxima ocasión: «no voy a dar así / como así / lo único que tengo / al día, / bibliografía». Pasados ya sus años de plenitud, y muy dentro de la tónica postmodernista, este sujeto va a sacarle más provecho a la mejor arma con que cuenta a su edad, el atractivo de lo intelectual convirtiendo de este modo el saber, que en el metarrelato modernista se suponía desinteresado, en una mercancía (Sagredo Saldaña, No todo es superficie, p. 37). La «Espada de los libros» a que aludió en el poema programático «Lo nunca visto» (pp. 15-16) adquiere aquí un sentido concreto y paródico: los libros, las bibliografías no son sólo instrumentos para obtener conocimientos desinteresados sino armas para la conquista sexual.

El título «Epístola inmoral de L.» (pp. 68-70) evidencia su parodia de la «Epístola moral a Fabio» de Andrés Fernández de Andrada (fl. ca. 1610). Mientras Andrada le aconseja a Fabio sobre el modo más moral de vivir y sobre cómo asumir la brevedad de la vida y rechazar sus vanidades, el anónimo remitente L. en la epístola de Molina Foix no dispensa consejos morales sino que exige un rendimiento de cuentas. La amplitud moral en la carta de Andrada se parodia en el empequeñecimiento de todos los participantes en la de Molina Foix: del autor por su avaricia, del receptor por su disposición a humillarse por un amor que no lo merece y del amor convertido en mera transacción mercantil. Lo que en cierto modo redime la situación se halla en el narrador quien persiste en amar a pesar del rampante mercantilismo.

En torno al lenguaje, los poemas tratan de la relación entre arte y vida desbancando toda pretensión de arte elitista. «Writer's Block» (pp. 43-44) parodia y minimiza el topos del poeta romántico que, a lo Bécquer, lucha con el idioma rebelde y mezquino. Y la falta de inspiración es extrema pues ni siquiera encuentra en el idioma propio una expresión que lo describa teniendo por ello que recurrir al inglés. El hablante aquí no experimenta la angustia propia en el lugar común de la página en blanco ni se cuestiona sobre la naturaleza del signo lingüístico. Al contrario, y de manera muy pragmática, 
apela al amor como tema muy socorrido en estos casos: «Eres un formidable paño / de las lágrimas / de la página en blanco». El amor será el tema donde enjuagar las lágrimas de la página en blanco, no por haberlo sentido y vivido, sino como tema con que combatir la falta de inspiración. Por eso el «querer» o la experiencia del amor y el «decir» que se quiere, o su expresión en palabras, no se diferencian.

«Cuatro naturalezas muertas y un paisaje», cuarta sección de Los espías del realista, pone en el tablero la relación entre arte y vida. En «Pez fuera del agua» (pp. 91-92), el pez nadando en la pecera es parte de un aparador donde otros elementos (la bandeja de copas de cristal de Bohemia, el frutero de loza nacional etc.) constituyen un conjunto que tiene más de naturaleza muerta que el mismo pez en la pescadería, víctima de las redes de los humanos. Tanto el pez vivo como sus dueños, el matrimonio sin hijos, viven en una pecera-apartamento controlados por las convenciones sociales. El de la pescadería, aunque muerto, está más vivo o es más verdadero porque al menos se arriesgó. En «Fragmento de una col» (p. 94), la forma de la col le inspira semejanzas con cosas animadas, como una oreja, una espiral de carne que respira o un cuerno de abundancia. El animismo llega a tal punto que comerla equivaldría a cometer antropofagia pues al morderla se oiría «al fondo / la queja del azar / que tardó siglos / en darte forma». Esta col se proyecta estereoscópicamente mostrando ante la vista sólo un mero fragmento de todas las formas previas que han entrado a formar su diseño actual. La referencia al azar y su participación en la forma de la col sugiere que tanto en la vida como en el arte hay aspectos no controlados por la técnica o la razón.

La quinta sección incluye poemas en torno a la cuestión del arte y su autonomía, por un lado, y de la vida, por otro. Desde distintos ángulos cada poema parodia las pretensiones elitistas del modernismo. En «Matrimonio de razón» (pp. 101-103) el título sugiere su opuesto, «pasión», y trae a la mente otros tipos de matrimonios: civiles, eclesiásticos, in articulo mortis, de conveniencia, resaltando lo inusitado de esta nueva combinación. Al tratarse del matrimonio del poeta con su escritura, este «matrimonio de razón» sugiere el hipotexto de Juan Ramón Jiménez y su poema programático «Vino primero, pura». Molina Foix desarrolla dicha relación desde un juvenil idilio del poeta con una misma metáfora, sus primeros escarceos sexuales con ella hasta llegar a la cópula y el subsiguiente aburrimiento matrimonial. La relación se agota en sí misma por carecer de variedad vital parodiando el final triunfalista de Juan Ramón: «Mía, desnuda para siempre». Para el sujeto de Molina Foix, mantenerse en una relación con la poesía donde se elimina lo vital no puede llevar más que al aburrimiento o al desenlace violento del escritor destrozando todos sus escritos, al darse cuenta de que lo que creyó valioso y original resulta «[d]el más viejo espectáculo, / el del agravio sólo comparativo». La originalidad es un mero sueño de orgullo juvenil que tarde o tempra- 
no el poeta reconoce como tal, agraviado al comparar lo que creyó su obra única con lo ya escrito.

En «Después de Coleridge» (pp. 104-105) el sujeto deja de lado el lápiz y su tinta negra, signos de una escritura centrada en su identidad como un sistema constituido por signos, para meterse más de lleno en otro discurso, otra caligrafía que implica las vigilias, las noches pasadas lidiando con los sentimientos propios más que con un sistema abstracto. A diferencia de «Writer's block» (pp. 43-44) donde se recrea la situación del escritor ante la página en blanco, hay aquí una identificación entre escritura y vida, entre el papel donde se escribe y el que el sujeto se asigna en su propia vida, es decir, el de asumir el rol de protagonista (la «auto-ficción»). La inspiración que el sujeto siente dentro de sí no es la de un Pegaso con alas transportándole a alturas trascendentes; su caballo no tiene alas pues escribe con los dedos, en contacto directo con la experiencia. Y si bien la escritura tiene lugar por la noche, y el sujeto se apoya en lo que aprende de toda la tradición literaria («Tu espalda es buena, / hoja impresa del libro sabido»), el resultado «sólo el día puede leer» pues tiene sentido en el recinto de la lógica diurna. Se propone, entonces, una escritura que participa tanto de la inspiración nocturna y posiblemente libre del control lógico como del orden racional y diurno.

Coleridge, junto con Wordsworth, se enfocó en el lenguaje común frente a las reglas retóricas del siglo XVIII y ambos poetas definieron la poesía como un arte cuya fuerte carga de emoción se debía articular en tranquilidad, no bajo el influjo directo de la pasión. Wordsworth dijo que la poesía es «the spontaneous overflow of powerful feelings from emotions recollected in tranquility», y Coleridge exhortó a los poetas a tomar prestado de la naturaleza pero a escribir «from recollection, and trust more to the imagination than the memory ${ }^{11}$. Coleridge creía en la imaginación como el poder más alto en el proceso creativo (Ford, p. 186), y postulaba que los trabajos procedentes de esa fuente debían escribirse en un lenguaje llano y sencillo. Por eso en «Estrecho entre dos aguas» (pp. 108-109), el sujeto de Molina Foix ataca al que cultiva el lenguaje como si fuera arte de la miniatura. El cuidado extremo al detalle, al giro de la frase, a la mesura, a la expresión menor es un arte que Molina Foix rechaza con pasión por su entrega a lo formal en detrimento de la vida. Al proclamar a los cuatro vientos el carácter derivativo de este arte, el sujeto de Molina Foix pone en evidencia lo que más teme este tipo de escritura, el ir en contra de las buenas costumbres, es decir, el «salirse del tiesto». «Antinoo ciego» (pp. 114-115), sobre el joven muy bello y favorito del

${ }^{11}$ Las referencias a Coleridge se encuentran en el sitio de la red indicado en la bibliografía. Molina Foix debe admirar en Coleridge el basarse en los «facts of mind», su creencia en el origen sensorial de los contenidos mentales y en la necesidad de una síntesis de mente y sentimientos. Coleridge buscaba una totalidad poética que incluyera un juicio siempre despierto y un autocontrol firme junto con entusiasmo y sentimiento profundo y vehemente (Ford, pp. 187-189; 193, 195). 
emperador Adriano ahogado en el Nilo en el 130 AJ., y en cuyo honor el emperador fundó la ciudad de Antinnopolis y erigió templos en su memoria, trata de la compenetración que siente el hablante con una escultura del joven. Pero la magia de esta compenetración se rompe con la llegada de «los zapatones del vigilante» del museo y el apagón de las luces que iluminaban la obra al ser la hora de cierre. Sin la luz, la estatua pierde su magia revelando su teatro de fingimiento: «Y sin el artificio de las luces eléctricas / no eres nada. / El arte del artista cesa en el pedestal... / Yo salgo de la sala / detrás de los turistas / que han dado con tu imagen / buscando a un dios más cuerdo». El poema parodia el «momento intemporal» de T.S. Eliot o la epifanía de Joyce, es decir, la distancia modernista del enclave circunstancial. Al salir del museo, el sujeto deja atrás el arte en su pedestal en busca del «dios más cuerdo» de la vida en el aquí y el ahora.

La cuestión de arte y vida se continúa en los doce «Sonetos del contrariado» incluidos en la segunda colección de poemas de Molina Foix titulada Vanas penas de amor (1998). Como señala García Posada (p. 19), la vuelta al formalismo métrico es rasgo común entre los nuevos poetas, y para Martínez Moreno (p. 53) delata el deseo de mostrar la simulación implícita en todo arte $^{12}$. Según Molina Foix, el título Vanas penas de amor procede de la obra de Shakespeare Love's Labors' Lost, por lo que se podría haber titulado también Vanas faenas de amor. En ambas versiones se retiene el sentido de futilidad aplicado al amor sustituyendo o yuxtaponiendo «labors» (trabajos o esfuerzos) por «penas» o dolores. En el caso de «faenas» no sólo se alude a «esfuerzos» sino también a líos y complicaciones. Cualquier sentido trascen-

\footnotetext{
${ }^{12}$ Por las fechas de publicación de sus libros $(1990,1998)$, la poesía de Molina Foix participa de las características de la llamada nueva o reciente poesía. En su antología de 1992 Luis Antonio de Villena destaca el «sesgo clásico en la última poesía»; la de García-Posada de 1996 se enfoca en el período que va de 1975 a 1992 identificando como rasgos de esta poesía su carácter urbano, su gusto por el formalismo métrico, el desencanto, la ficcionalización del yo poético, la quiebra del sentido romántico de originalidad... En 2003 Darío Villanueva discute los «nuevos nombres 1975-1990» señalando, además de los rasgos ya mencionados, el gusto por la narración y por la «recreación». En su antología de 2001, Cano Ballesta se enfoca en el período entre 1980 y 2000, mientras que su libro de 2007 abarca de 1970 a 2005 . El crítico destaca en estos poetas el papel de la experiencia, de la ironía y el pastiche, y el paso del culturalismo a la vida. Estos rasgos se encuentran también en autores británicos de las décadas de los 50 y 60 (Alan Sillitoe, Kingsley Amis y Philip Larkin), quienes rechazaron el elitismo del modernismo para escribir desde la propia experiencia. Analizando la sensibilidad postmoderna en las obras de artistas contemporáneos, Saldaña señala la sustitución de «los grandes modelos teóricos de conocimiento y explicación del mundo ... por el análisis de casos prácticos mucho más concretos y delimitados» («Postmodernidad, todo vale», pas. 352-353), lo cual se aplica bien a los poemas de Molina Foix. Juan José Lanz, por su parte, señala la distancia que separa a los novísimos de su última producción poética donde, como ya indicó Villena, se da la «vinculación entre cultura y vida», y entre la pluralidad de tendencias, «una línea irónico-realista» bien presente en Molina Foix (pp. 270, 274).
} 
dente que pueda tener el amor, y el esfuerzo, dolor y complicaciones que conlleva, se desmantela al alegar su futilidad. Y si se piensa en hipotextos como los sonetos de amor de Shakespeare, o incluso los del amor oscuro de Lorca, por ejemplo, la contrariedad aquí no se debe al dolor causado por el amor no correspondido o víctima debido a la represión social, sino a la frustración de constatar que las expectativas respecto al amor y su grandeza no encuentran eco en la experiencia personal. «Criatura» (p. 92) es una parodia cómica del mito de Pigmalión y Galatea. A diferencia del legendario rey de Chipre quien por la intercesión de Venus logró que su estatua se convirtiera en mujer de carne y hueso, este poeta querría que sucediera lo opuesto, es decir, conseguir una estatua o muñeco con algún mecanismo eléctrico para obtener su placer evitando así los aspectos menos edificantes del contacto sexual de los cuerpos. El problema con la idea del muñeco es que se podría producir un cruce de cables, alguna avería y entonces se convertiría «en porquería / lo que se quiso sexo limpio y sano». Por lo que se ve obligado a admitir que «No hay un remedio claro, panaceas, / para el choque de cuerpos simple y llano». El sujeto tiene que conformarse con su amante de carne y hueso pues aunque tenga las piernas algo feas, no corre el riesgo de ser electrocutado al besarlo. La tecnología del mundo moderno, como la asepsia del arte clásico no puede suplantar la realidad de la naturaleza, de la carne.

En «Catálogo» (p. 94) esa realidad adquiere uno de sus rasgos más siniestros pues si en el mito de Pigmalión el cuerpo de carne y hueso excede con creces a la estatua, en «Catálogo» el contacto de la carne trae consigo la posibilidad de enfermedades mortales. El poema se inscribe sobre el discurso de Don Giovanni de Mozart y su catálogo de 1003 conquistas, un record de logros que numerosas obra de literatura y música han registrado ${ }^{13}$. Comparándose con las 1003 conquistas de Don Giovanni, el sujeto de Molina Foix da cuenta de 225 anotaciones en poco más de un año que, sin embargo, no han ocurrido sin consecuencias pues seis veces ha tenido que purgarse por enfermedades contraídas. La rima consonante entre «anotaciones» y «purgaciones» señala la cercanía entre el placer sexual desmesurado y la enfermedad. «Amor y tecnología» (p. 96) evoca el título Amor y pedagogía, novela de Miguel de Unamuno publicada en 1902 sobre Don Avito Carrascal que cree que puede hacer de su hijo un genio si aplica los principios modernos de la pedagogía. Los resultados de tal experimento son trágicos pues su hijo se suicida. La sociología positivista que critica Unamuno se representa en el poema en la tecnología, específicamente en la máquina de escribir Olivetti y el PC que el poeta usa para escribir sus obras. Cansado de tener que compartirse con la Olivetti, su primer amante le tira la máquina por la ventana. Tal método «pe-

${ }^{13}$ La referencia procede del aria «Madamina, il catalogo è questo» (Acto I, escena V) que Leporello, el criado de Don Giovanni le canta a Elvira, una de las damas abandonadas por el seductor. 
dagógico» tuvo sus resultados pues el hablante aprendió la lección: cesó de teclear por la noche y cumplió en la cama. Sin embargo de poco le sirvió pues el amante, aún con esta regeneración, lo dejó. Aún así la lección no se dio por perdida pues, como dice al final: «Ahora si me enamoro voy de duro: / con póliza de riesgo en mi PC». Si Unamuno criticó el positivismo y sus posibles efectos devastadores en el ser humano, Molina Foix apela al sentido práctico. La tecnología es una necesidad innegable. Si entra en conflicto con la vida amorosa, la solución no está en deshacerse de ella sino en protegerse.

«Talento» (p. 97) parodia la expresión popular: «Genio y figura hasta la sepultura». El soneto relata la relación con un amante de gran atractivo sexual descrito en conexión con Petronio, autor de la novela picaresca Satiricón, y su joven protagonista, Gitón. Las palabras inglesas sexy y exit proporcionan un aire actual y despreocupado a la relación mientras que su rima indica la rapidez con que la relación terminó, desde la inicial atracción por este amante «sexy» a su final «exit». El joven se dio al «exit» al ver que sólo lo sexual contaba en la relación, no «lo que tengo en la cabeza». A los reproches del amante, el sujeto responde sin miramientos en el terceto: «Te diré la verdad más simple y pura, / alcanzada tras larga reflexión: / lo tuyo no es el genio, es la figura». El juego entre la brevedad (de lo dicho) y la largura (de la reflexión) parodia la brevedad de la relación y del ingenio del amante con respecto a la «largura» de su figura o atractivo.

Los poemas de Molina Foix contienen relatos, observaciones, recuentos de experiencias sexuales en consonancia con lo que Foucault llama la scientia sexualis del Occidente frente a la ars erotica del Japón, China e India. Si en estas culturas se busca multiplicar los placeres, el occidente se afana en confesar y escudriñar los deseos (pp. 69-98). Esta fuerte tendencia a hablar sobre el sexo, que Foucault identifica especialmente en los tres últimos siglos, no es sólo consecuencia de la moral sino parte del discurso y la exploración racional y analítica propia de la cultura occidental (pp. 29-30). Molina Foix continúa a su modo esta tradición aunque partiendo de la creencia de que, como diría Barthes, todo discurso en su monumentalidad puede ser desbancado y cuestionado en base de la experiencia personal y humana (Culler, Structuralist Poetics, p. 134). Al establecer un paralelo entre los grandes discursos de la cultura y la experiencia personal, lo literario se humaniza y reevalúa (Barthes, Essais critiques, pp. 138-139). Este acercamiento a los grandes textos del Occidente no es nuevo en Molina Foix quien ya en su poética de la antología de Castellet indicó la necesidad de desterrar «la vanagloria de la palabra» (p. 183). Esta poesía rechaza los presupuestos modernistas de elitismo y autonomía del arte, enfocándose en experiencias que si no han sido «realmente» vividas no sería difícil considerarlas como tal. En su parodia de textos magistrales de la cultura, estos poemas hacen hincapié en la idea de juego, de proponer una pequeña narrativa donde la profundidad se descarta a 
favor de la superficie ${ }^{14}$. Los poemas se gozan en manifestar su carencia de preocupaciones transcendentales pues, como sucede en el postmodernismo, se desconfía de la idea de profundidad postulando que la verdad reside en la superficie, que la apariencia es lo que es. Y como las apariencias del mundo son volubles y múltiples, no hay ninguna pretensión de lograr una verdad única y definitiva. Ya en la poética para la antología de Castellet Molina Foix indicó la necesidad de desvelar claves poéticas aún vigentes en poetas del pasado pero dotándolas de significados propios (p. 182). Este autor se encuentra sólidamente entroncado en la tradición cultural y literaria pero sin considerarla como la verdad última y definitiva. A diferencia de los poetas de la experiencia, sus historias personales no están exaltadas sino más bien «recicladas» con desenfado e ironía. En lo que respecta al mito, el reciclaje sirve para «iluminar una experiencia humana de nuestros días» (Cano Ballesta, Nuevas voces, pp. 65, 84).

En torno al «Corazón», a la «Espada» de los libros y al campo «Oscuro» del lenguaje vivo, Molina Foix elabora una poesía paródica donde nociones de amor ideal y único, de elitismo intelectual y de autonomía del arte se vienen abajo. Como Ovidio, Molina Foix presenta una perspectiva marcada por la movilidad de amores y discursos. Ambos poetas son conscientes de la máscara que supone la sinceridad y que la «verdad» ya viene marcada por capas de significación. Hay en ambos mucho de pose que más que falsedad implica la creencia de que el idioma y la propia subjetividad son indisolubles de la retórica y que dependen tanto de lo que se pueda sentir «realmente» como del estilo. García-Posada se refiere a esta quiebra del esteticismo y de la noción romántica del amor y de la originalidad creativa como una «poética ... de corte temporalizante, realista, histórico, lejos de cualquier dogmatismo» (pp. 14-15). El humor y la ironía son ingredientes necesarios en la perspectiva de esta poesía (pág. 18), además de lo que Villanueva señala como preferencia por los procedimientos retóricos «invisibles», los que no parecen existir (p. 95). La parodia en Molina Foix responde a lo que la crítica encuentra en dicho género de epistemología de la contemporaneidad al señalar la disparidad entre los ideales del mundo clásico, de la literatura, arte, filosofía, de los grandes discursos del sistema analítico referencial y la realidad del mundo actual ${ }^{15}$.

${ }^{14}$ Steven Connor discute con detalle la cuestión de profundidad/superficialidad en el postmodernismo comentando al respecto el trabajo de Alan Wilde y Hassan (véanse pp. 114117 y 111-112).

${ }^{15}$ Hutcheon considera que «parody in this century is one of the major modes of formal and thematic construction of texts» (Theory, p. 2). Según Galván y González Doreste, la índole contradictoria «es evidentemente lo que hace de la parodia el género de la contemporaneidad, el genero dialógico y polifónico por excelencia, el que amalgama en sí las formas opuestas de arte elevado (modernista) y arte popular» (pp. 113, 116). 


\section{REFERENCIAS BIBLIOGRÁFICAS}

BARTHES, Roland. «La métaphore de l'oeil». Critique, n. ${ }^{\text {os }}$ 195-196 (1963) pp. 770-777.

—. Essais critiques. Paris: Seuil, 1964.

—. Fragments d'un discourse amoureux. Paris: Seuil, 1977.

BATAILLE, Georges. Histoire de l'oeil. Paris: Flammarion, 1998.

BELTRÁN ALMERÍA, Luis. «Notas para una teoría de la parodia». En La parodia. El viaje imaginario. Actas del IX simposio de la sociedad española de literatura general y comparada, (Zaragoza 18 al 21 de Noviembre de 1992), v. II. Zaragoza: Universidad de Zaragoza, 1994, pp. 49-56.

CANO BALleSTA, Juan. Poesía española reciente (1980-2000). Madrid: Cátedra, 2001.

- Nuevas voces y viejas escuelas en la poesía española (1970-2005). Granada: Atrio, 2007.

CASTELlET, J. M. Nueve novísimos poetas españoles. Barcelona: Península, 2001.

COLERIDGE, Samuel Taylor. Disponible en <http://www.brainyquote.com/quotes/authors/ s/samuel_taylor_coleridge.html>

CONNOR, Steven. Postmodernist Culture. An Introduction to Theories of the Contemporary. Oxford, UK: Blackwell, 1989.

CULLER, Jonathan. The Pursuit of Signs. Semiotics, Literature, Deconstruction. Ithaca, Nueva York: Cornell UP, 1981.

-. Structuralist Poetics. Structuralism, Linguistics, and the Study of Literature. Ithaca, Nueva York: Cornell UP, 1975.

ECO, Umberto. Postille a «Il nome della rosa». Roma: Bompiani, 1984.

FERNÁNDEZ DE ANDRADA, Andrés. «Epístola moral a Fabio». En RIVERS, Elias L. (ed.). Poetry of Spain. New York: Charles Scribner's Sons, 1966, pp. 251-258.

FORD, Boris (ed.). From Blake to Byron. Pelican Guide to English Literature. v. V. Great Britain: Penguin Books, 1972, pp. 186-206.

FOUCAULT, Michel. Histoire de la sexualité, tome 1: la volonté du savoir. Paris: Gallimard, 1976.

FUSS, Diana, «Inside/Out». En FUSS, Diana (ed.). Inside / Out. Lesbian Theories, Gay Theories. Nueva York y Londres: Routledge, 1991, pp. 1-10.

GALVÁN, Fernando; GONZÁLEZ DORESTE, Dulce María. «El uso contemporáneo de 'parodia'». En La parodia. El viaje imaginario. Actas del IX simposio de la sociedad española de literatura general y comparada, (Zaragoza 18 al 21 de Noviembre de 1992), v. II. Zaragoza: Universidad de Zaragoza, 1994, pp. 111-118.

GARCÍA-POSADA, Miguel. La nueva poesía (1975-1992). Barcelona: Crítica, 1996.

GARVIN, Harry R. (ed.). Romanticism, Modernism, Postmodernism. Lewisburg, PA: Bucknell UP, London, Associated P, 1980.

GENETTE, Gérard. Palimpsestes. La littérature au second degrée. Paris: Seuil, 1982.

GÓMEZ-MONTERO, Javier. «Poética de la posmodernidad y praxis de la parodia en Poesía (1970-1989) de Luis A. de Cuenca». En La parodia. El viaje imaginario. Actas del IX simposio de la sociedad española de literatura general y comparada, (Zaragoza 18 al 21 de Noviembre de 1992), v. II. Zaragoza: Universidad de Zaragoza, 1994, pp. 133 151.

GREEN, Peter. «Introduction». En Ovidio. The Erotic Poems. Great Britain: Penguin Books, 1982, pp. 15-81.

HUTCHEON, Linda. A Theory of Parody. The Teachings of Twentieth-Century Art Forms. Nueva York y Londres: Methuen, 1985.

-. A Poetics of Postmodernism. History, Theory, Fiction. Nueva York y Londres: Routledge, 1988.

JAY, Martin. «In the Empire of the Gaze: Foucault and the Denigration of Vision in $20^{\text {th }}$ Century French Thought». En APPIGNANESI, Lisa (ed.). Postmodernism. ICA Documents. Londres: Free Association Books, 1989, pp. 49-74. 
KOSINSKI, Jerzy. «Death in Cannes». Esquire (March 1986), pp. 81-89.

KRISTEVA, Julia. «Postmodernism?». En Harry R. Garvin (ed.). Romanticism, Modernism, Postmodernism. Lewisburg, PA: Bucknell UP, 1980, pp. 136-141.

LANZ, Juan José. La poesía durante la transición y la generación de la democracia. Madrid: Devenir Ensayo, 2007.

MARTÍNEZ MORENO, Isabel. «Dionisio Cañas. El sujeto poético posmoderno». Insula, n. ${ }^{\text {os }} 512-513$ (agosto-septiembre 1989) pp. 52-53.

MOI, Toril (ed.). The Kristeva Reader. Nueva York: Columbia UP, 1986.

MOLINA FOIX, Vicente. El vampiro de la calle Méjico. Barcelona: Anagrama, 2002.

—. Vanas penas de amor. Barcelona: Plaza \& Janes, 1998.

—. La mujer sin cabeza. Barcelona: Plaza \& Janés, 1997.

—. Los espías del realista. Barcelona: Península, Edicions 62, 1990.

REISS, Timothy J. The Discourse of Modernism. Ithaca y Londres: Cornell UP, 1982.

RIFFATERRE, Michael. Semiotics of Poetry. Bloomington \& Londres: Indiana UP, 1978.

SAGREDO SALDAÑA, Alfredo. «Postmodernidad, todo vale, aunque de nada sirva». Tropelías: Revista de teoría de la literatura y literatura comparada, n. ${ }^{\text {s }}$ 5-6 (1994-1995) pp. 349-369.

—. «Poesía española postmoderna: la tradición traicionada». Verbo hispánico: anuario. Departamento de la Lengua y Literatura Españolas de la Facultad de Filosofía y Letras de la Universidad de Ljubljana. 2001, n. ${ }^{\circ}$ 9, pp. 145-154.

- No todo es superficie. Poesía española y postmodernidad. Valladolid: Universidad de Valladolid, 2009.

VILLANUEVA, Darío. «Los marcos de la literatura española 1975-1990: esbozo de un Sistema». En RICO, Francisco (ed.). Historia y Crítica de la Literatura Española. Tomo IX: Los nuevos nombres: 1975-1990. Barcelona: Crítica, 2003, pp. 26-38.

VILLENA, Luis Antonio de. Fin de siglo (El sesgo clásico en la última poesía española). Madrid: Visor, 1992.

Fecha de recepción: 12 de febrero de 2009

Fecha de aceptación: 13 de noviembre de 2009 